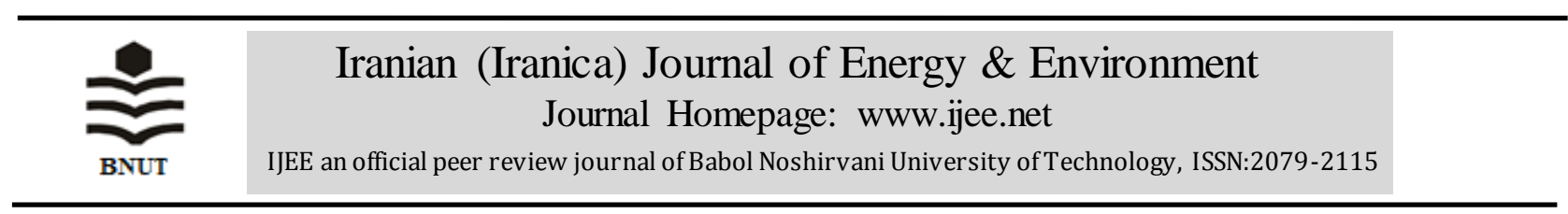

\title{
Micro-properties of Molding Products between Modified Corn Stalk and Pulverized Coal
}

\author{
C. Juan ${ }^{1,2 *}$, Y. Haijun 3 ,L. Hao ${ }^{1,2}$,Z. Zhifang1,2,L. Mei ${ }^{1,2}$ \\ ${ }^{1}$ School of Chemistry and Chemical Engineering, Yulin University, Yulin, Shannxi, China; \\ ${ }^{2}$ Shaanxi Key Laboratory of Low Metamorphic Coal Clean Utilization, Yulin, Shannxi, China \\ ${ }^{3}$ National Coal and Salt Chemical ProductQuality Supervision and Inspection Center,Yulin, Shannxi, China
}

\section{$P A P E R I N F O$}

\section{Paperhistory:}

Received 05 May 2019

Accepted in revised form 24 June 2019

\section{Keywords:}

Binder

Briquette

Corn Stalk

Formed Coke

Micro-Properties

Molding

\begin{abstract}
$A B S T R A C T$
Taking Shanxi fat coal, Shanxi 4\# coke coal and Shenmu low rank pulverized coal as raw materials, three different concentrations of $\mathrm{NaOH}$ modified corn stalk were used as binder. The effect of changing $\mathrm{NaOH}$ concentrations and coal particle size used in moulding briquette and formed coke on its SEM micrographs, combustion property and FTIR absorption strength were investigated. The micro-properties of corn stalk before and after modification was also discussed. Results showed that the moisture content and ash yield of modified corn stalk increased obviously and the volatile yield showed opposite trend. $2.0 \% \mathrm{NaOH}$ modified corn stalk showed more voids or porosity which could wrap a large number of coal particles to form strong strength briquette. Addition of modified corn stalk could reduces the briquette burning time and increased burning rate with strong flame and good ignition. From SEM micrograph, briquette had rough surface, and different sizes coal particles and fiber were bound together firmly. Formed coke showed light gray metallic luster, light mass, obvious circular holes and small gaps among particles. The melting colloid and binder could better infiltrate and encapsulate coal particles to form a dense and impermeable entity, which blocked the channels of organic group decomposition during pyrolysis process. Thus, it is forming many holes of differ ent sizes on the surface and inside formed coke. The infrared spectrum of formed coke was simplier than briquette, and the absorption peak number was less and absorption strength was weaker also.
\end{abstract}

doi: $10.5829 /$ ijee.2019.10.02.01

\section{INTRODUCTION}

China's energy endowment characteristics is short oil, less gas and rich coal. Therefore, the coal undertakes the main status of energy supply for long time. Its great contribution to the social economy can not be neglected [1]. In particular, the low metamorphic coal resources in Northern Shaanxi are rich and enjoy high prestige of "one of the eight largest coal fields in the world" [2]. However, the lump coal yield accounts for merely $25 \%$ [3] of coal total yield because of the increase of mechanical mining ratio and the way of mechanical transportation. The pulverized coal yield is huge which can not be used efficiently [4]. Thus, the pulverized coal forming technology with high efficiency and clean utilization is imperative [5-7].

Biomass resources are widespread, lower price, renewable, and there is no secondary pollution. When fossil energys such as coal, oil and natural gas disappear, it is the world of biomass energy. In recent years, many scholars at home and abroad have prepared briquette and formed coke with biomass as binder, and obtained certain research results
[8-10]. So, efficient and clean utilization of low metamorphic pulverized coal and agricultural wastes can be realized to reduce pollutant emission [11]. Corn stalk is rich in cellulose as a precious biomass resource, but it has not been effectively utilized for a long time. Therefore, the briquette and formed coke are prepared with modified corn stalk as binder in this paper, which was rarely reported in the literature.

Currently bio-briquette research mainly have been focused on the binder cohesiveness and briquette macrostrength, only a little study provided a research on microscopic properties of modified corn stalk and briquette. Meanwhile, briquetting mechanism was not clear enough. Huang Guangxu et al. [13] have pointed out that the existence of biomass fiber network structure and viscous liquid were the key to briquetting of bio-briquette. Chen Lunjian [14] has proposed that there were various kinds of crystals on the coal surface and pores. The crystals connected with each other to form a crystal network, and coal particles were embedded in it to form a certain strength briquette.

Thus, this research is aim to explore micro-properties of modified corn stalk, briquette and formed coke. The

\footnotetext{
* Corresponding Author Email: chenjuanchen1985@ 163.com(Chen Juan)
} 
research uses low metamorphic pulverized coal in Yulin area as raw material, $\mathrm{NaOH}$ modified corn stalk as binder, and biobriquette are prepared by the dry cool state briquetting process. Then formed coke are derived from directly hightemperature pyrolysis of bio-briquette. The microscopic structure and properties of modified corn stalk, briquette and formed coke was investigated by FTIR, SEM. The forming mechanism of pulverized coal and modified corn stalk was discussed also. The results may provide guidance for clean and efficient utilization of low metamorphic pulverized coal and waste corn stalk in Northern Shaanxi.

\section{MATERIAL AND METHODS}

\section{Materials}

The low metamorphic coal in this research was obtained from Shiyaodian Coal Mine of Shenmu City (Shenmu Coal for short), Shaanxi Province in China. Prior to analys is, the coal samples were dried, milled and sieved into $3-1.5 \mathrm{~mm}$ and < $0.074 \mathrm{~mm}$. The Shanxi fat coal and Shanxi $4 \#$ prime coking coal were milled below $3 \mathrm{~mm}$ and stored in bottle to reserve. Corn stalks were obtained from rural areas of Yulin, and were also broken below $3 \mathrm{~mm}$ after natural drying. The basic properties of coal was measured based on air dried basis. Coal proximate analysis data is listed in Table 1.

Three kinds of corn stalk binder were prepared by adding $5 \%$ corn stalk into three reactors with a certain concentration of $1.5,2.0$ and $2.5 \% \mathrm{NaOH}$, respectively and heating at $80^{\circ} \mathrm{C}$ for $2 \mathrm{~h}$. Shanxi fat coal, $4 \#$ prime coking coal and Shenmu coal were fully mixed in a ratio of $2: 2: 5$, and $10 \%$ corn stalk binder was added, which was put into the molding machine. The cylindrical briquette with $50 \mathrm{~mm}$ in diameter and $8-9 \mathrm{~mm}$ in length was obtained under the pressure of $20 \mathrm{MPa}$ in $60 \mathrm{~s}$. Then briquette was put into drying box to dry at $105^{\circ} \mathrm{C}$ until constant weight. Coking the briquettes, formed coke was done by muffle furnace using a heating rate of $5^{\circ} \mathrm{C} / \mathrm{min}$ from $20^{\circ} \mathrm{C}$ up to $900^{\circ} \mathrm{C}$ with a following dwell time of 3 hours at $900^{\circ} \mathrm{C}$ in inert atmosphere.

\section{Method}

The changes of functional groups were tested by the infrared spectra which was measured by infrared spectrometer (TENSOR 27, Bruker Company, Germany). The appearance of samples was observed by field emission scanning electron microscopy ( $\sigma 300$, Zeiss Company, Germany). Fully dried samples were sprayed with gold, and then put into the scanning electron microscopy to observe and took photos with different magnification times. The characteristic of surface area and aperture was tested by Surface Area and Aperture Measuring Instrument.

\section{Combustion property of briquette}

The briquette combustion property was tested by cylindrical combustion stove as shown in Figure 1. Breifly, this stove was a $48 \times 27 \mathrm{~cm}$ cylinder with a $12.5 \mathrm{~cm}$ diameter inner, metallic outer cover and the thermal barrier between the inner and the cover supplied by Yulin Future Energy Company, China. The boling water process was worked on $1000 \mathrm{~g}$ water poured in $20 \mathrm{~cm}$ diameter container. The water temperature was
TABLE 1. Coal proximate analysis

\begin{tabular}{|c|c|c|c|c|c|c|}
\hline \multirow{2}{*}{$\begin{array}{l}\text { Coal } \\
\text { sample }\end{array}$} & \multicolumn{4}{|c|}{ Proximate analy sis $\left(\mathrm{w}_{\mathrm{t}}\right)$} & \multirow{2}{*}{$\begin{array}{c}\text { Calorific } \\
\text { value } \\
(\mathrm{MJ} / \mathrm{kg})\end{array}$} & \multirow{2}{*}{$\begin{array}{l}\text { Caking } \\
\text { index }\end{array}$} \\
\hline & $\mathrm{M}_{\mathrm{ad}}$ & $A_{d}$ & $\mathrm{~V}_{\mathrm{daf}}$ & $\mathrm{FC}_{\mathrm{daf}}$ & & \\
\hline $\begin{array}{l}\text { Shenmu } \\
\text { coal }\end{array}$ & 5.45 & 8.27 & 36.16 & 63.84 & 22.57 & 10 \\
\hline Fat coal & 0.96 & 10.62 & 30 & 70 & 33.39 & 95.42 \\
\hline $\begin{array}{l}\text { 4\# coking } \\
\text { coal }\end{array}$ & 0.42 & 9.25 & 22.38 & 77.62 & 35.69 & 84.4 \\
\hline
\end{tabular}

recorded by thermometer installed in container and set up to middle of container without touching the container and also by using stop watch. Bring the container on the stove when the fire was ignited. For the relative characteristic of smoke, ash, flame and ignition observed by eye during the trial. Burning time was obtained by observing the mass changes recorded on mechanical balance and also by using stop watch. Thus the time of briquette combustion was completed. After known mass of total burnt briquette and burning time, average burning rate could be calculated using the following expression:

Burning Rate $=$ Total Mass of Burnt Briquette $(\mathrm{g}) /$

Burning Time (min)

\section{RESULTS AND DISCUSSION}

\section{Micro-properties of modified corn stalk}

Proximate analysis of modified corn stalk The proximate analysis of modified corn stalk acquired from three different concentrations $\mathrm{NaOH}$ and raw sample are listed in Table 2. Proximate analysis is presented the percentage of Fixed Carbon (FC), Volatiles (V), Ash (A), and Moisture Content (M). The amount of moisture content of modified corn stalk is higher than original sample. Due to the surface area and pore of modified corn salk increases after alkalization treatment, modified corn stalk can store more water. The moisture content of modified corn stalk increases with the increased of $\mathrm{NaOH}$ concentration. When $\mathrm{NaOH}$ concentration increases to $2 \%$, the highest moisture content is $5.85 \%$. This phenomenon brought that $2 \% \mathrm{NaOH}$ can decompose cellulose, hemicellulose and lignin at the maximum limit, and spatial structure is become loose under the condition of keeping corn stalk network structure.

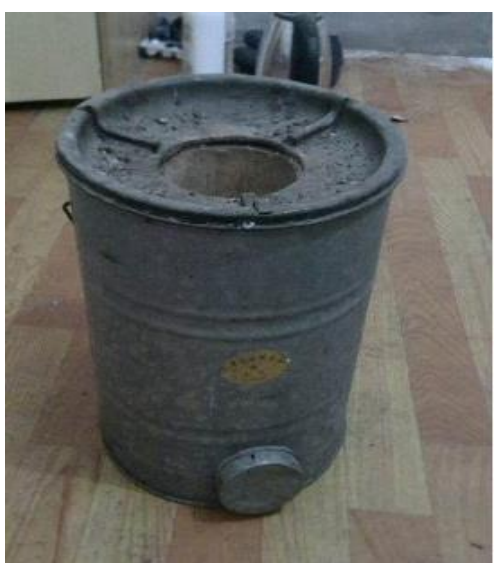

Figure 1. The cylindrical combustion stove 
TABLE 2. Modified corn stalk proximate analysis

\begin{tabular}{lcccc}
\hline $\begin{array}{l}\text { Binder sample } \\
\text { Proximate analysis } \\
/ \mathbf{w}_{\mathbf{t}} \%\end{array}$ & $\begin{array}{c}\mathbf{M}_{\mathbf{a d}} \\
/ \mathbf{w}_{\mathbf{t}} \%\end{array}$ & $\begin{array}{c}\mathbf{A}_{\mathbf{d}} \\
/ \mathbf{w}_{\mathbf{t}} \mathbf{\%}\end{array}$ & $\begin{array}{c}\mathbf{V}_{\mathbf{d a f}} \\
/ \mathbf{w}_{\mathbf{t}} \mathbf{\%}\end{array}$ & $\begin{array}{c}\mathbf{F C}_{\mathbf{d a f}} \\
/ \mathbf{w}_{\mathbf{t}} \%\end{array}$ \\
\hline $\begin{array}{l}\text { Corn stalk } \\
\begin{array}{l}1.5 \% \mathrm{NaOH} \text { modified } \\
\text { Corn stalk }\end{array}\end{array}$ & 5.32 & 3.42 & 18.69 & 81.31 \\
$\begin{array}{l}2.0 \% \mathrm{NaOH} \text { modified } \\
\text { Corn stalk }\end{array}$ & 5.85 & 5.78 & 11.37 & 88.63 \\
$\begin{array}{l}2.5 \% \mathrm{NaOH} \text { modified } \\
\text { Corn stalk }\end{array}$ & 5.62 & 6.23 & 15.11 & 84.89 \\
\hline
\end{tabular}

However, the moisture content decreases when the $\mathrm{NaOH}$ concentration increases to $2.5 \%$. The results showed that the original macromolecular fiber structure which plays supporting role in network is destroyed to some degree in high concentration alkali.

Compared with raw corn stalk, the ash yield of modified corn stalk increases obviously and the volatile yield shows opposite trend. Due to $\mathrm{NaOH}$ mainly decomposes organic components such as cellulose, hemicellulose and lignin from corn stalk, while inorganic minerals accumulate in solid phase, resulting in high ash yield and low volatile yield. The volatile yield of modified corn stalk increases with the increased of $\mathrm{NaOH}$ concentration. Due to high concentration of $\mathrm{NaOH}$ destroys the structure fully, the quantity of short chains and functional groups increases.

\section{FTIR analysis of modified corn stalk}

Figure 2 shows FTIR spectrum of corn stalk that modified with three different concentrations of $\mathrm{NaOH}$. The 1 4 curve belongs to raw corn stalk, $1.5,2.0$ and $2.5 \% \mathrm{NaOH}$ modified corn stalk, respectively. The strong and wide absorption peak at $3426 \mathrm{~cm}$ ${ }^{1}$ is $-\mathrm{OH}$ stretching vibration peak. Here the absorption peak strength of modified corn stalk is weaker than raw corn stalk, and the absorption strength of $2.5 \% \mathrm{NaOH}$ modified corn stalk is the weakest. Some -OH in corn stalk is consumed by itself due to its hydrolysis with $\mathrm{NaOH}$. Moreover, hydrogen bond is cracked to some degree in strong alkali. The absorption peak at $2990-2880 \mathrm{~cm}^{-1}$ belongs to C-H symmet-

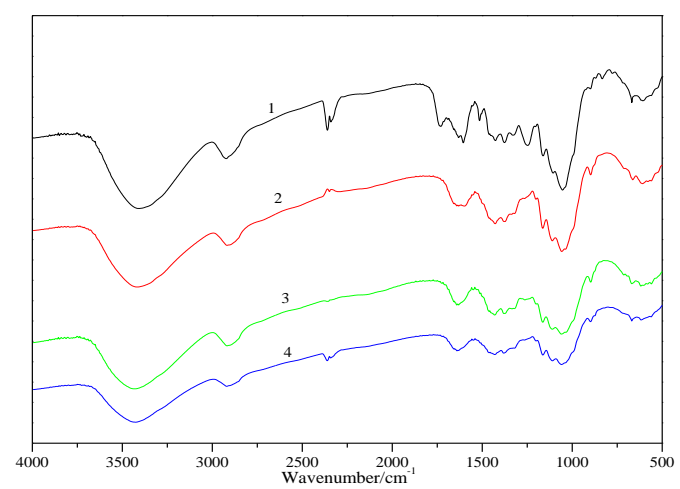

Figure 2. FTIR spectrum of corn stalk before and after modification ric or asymmetric stretching vibration in carbomethyl and methylene. Due to the propane structure in lignin breaks when it meets $\mathrm{NaOH}$, the strength of $-\mathrm{CH}_{2}$ asymmetric stretching vibration absorption at $2920 \mathrm{~cm}^{-1}$ decreases with an increase in $\mathrm{NaOH}$ concentration. The symmetrical or asymmetrical stretching vibration absorption peak of ionized carboxyl (COO-) is observed obviously in modified corn stalk near 1640 $\mathrm{cm}^{-1}$ and $1440 \mathrm{~cm}^{-1}$. This phenomenon indicates that $\mathrm{NaOH}$ modification can take some carboxy group into binder. Due to aromatic ring is stable and not easily decomposed by $\mathrm{NaOH}$, the aromatic $\mathrm{C}=\mathrm{C}$ of benzene ring skeleton has a vibrational absorption peak at $1510 \mathrm{~cm}^{-1}$. The absorption peak at $1164 \mathrm{~cm}^{-1}$ is C-C skeleton stretching vibration of cellulose molecule. The ether C-O-C symmetrical stretching vibration absorption peak at $1073 \mathrm{~cm}^{-1}$ is weakened in modified corn stalk. The higher $\mathrm{NaOH}$ concentration, the weaker absorption is here. Thus, the C-O-C of hemicellulose and lignin is destroyed in high concentration $\mathrm{NaOH}$. In general, $2 \% \mathrm{NaOH}$ can expose more cellulose in corn stalk without destroying the basic chemical structure.

SEM micrographs of modified corn stalk Figure 3 illustrates detailed micro-information of corn stalk modified with different concentrations of $\mathrm{NaOH}$. Figure $3 \mathrm{a} \sim \mathrm{d}$ photo belongs to SEM micrographs of raw corn stalk, 1.5, 2.0 and $2.5 \% \mathrm{NaOH}$ modified corn stalk, respectively. Corn stalk remains its inherent macroscopic appearance basically after milling as shown in Figure 3a. That is to say, the cellulose is combined closely, and the epidermis is dense. However, the corn stalk epidermis appears some cracks obviously due to extruding or stretching during the millling process. The medullary cavity of corn stalk is broken, spilled on epidermis. The fiber texture appears clearly on the surface of modified corn stalk as shown in Figure 3b. Compared with Figure 3a, most particles and lignins are removed from corn stalk epidermis, which leads to more fibers exposure. The fiber arrangement is highly ordered as shown in Figures $3 \mathrm{~b}$ and $3 \mathrm{c}$. The structure change of $1.5 \% \mathrm{NaOH}$ modified corn stalk is so little, only some small cracks or voids appeared.

The surface of $2.0 \% \mathrm{NaOH}$ modified corn stalk shows more gully and fine fiber. Due to lignin, hemicellulose, pectin and tannin in raw corn stalk are extracted by alkali, more fine fibers are exposed, and the strong interaction among them leads to the appearance of fibrils cross linking, which plays bonding and tension effect in briquetting process [15]. In addition, the voids or holes makes the overall structure loose, which can wrap a large number of coal particles. Hence, the strong strength briquette obtains under high pressure. In Figure 3d, the original smooth and ordered surface disappeared completely. But lots of filament emerge clearly and many particulates scatter on the filament surface or gaps. This phenomenon can be thought the hydrolysis reaction between alkali and the outermost lignin is the first. Thus, the lignin is separated from the surface firstly [16]. Then alkali dis solve hemicellulose, carbohydrate and pectin which lead to liquid binder to be produced. Finally, some fibrocyte and parenchyma cells are separated due to the interaction between alkali and cellulose. These separated substances are scattered particulates as shown in Figure 3d. 


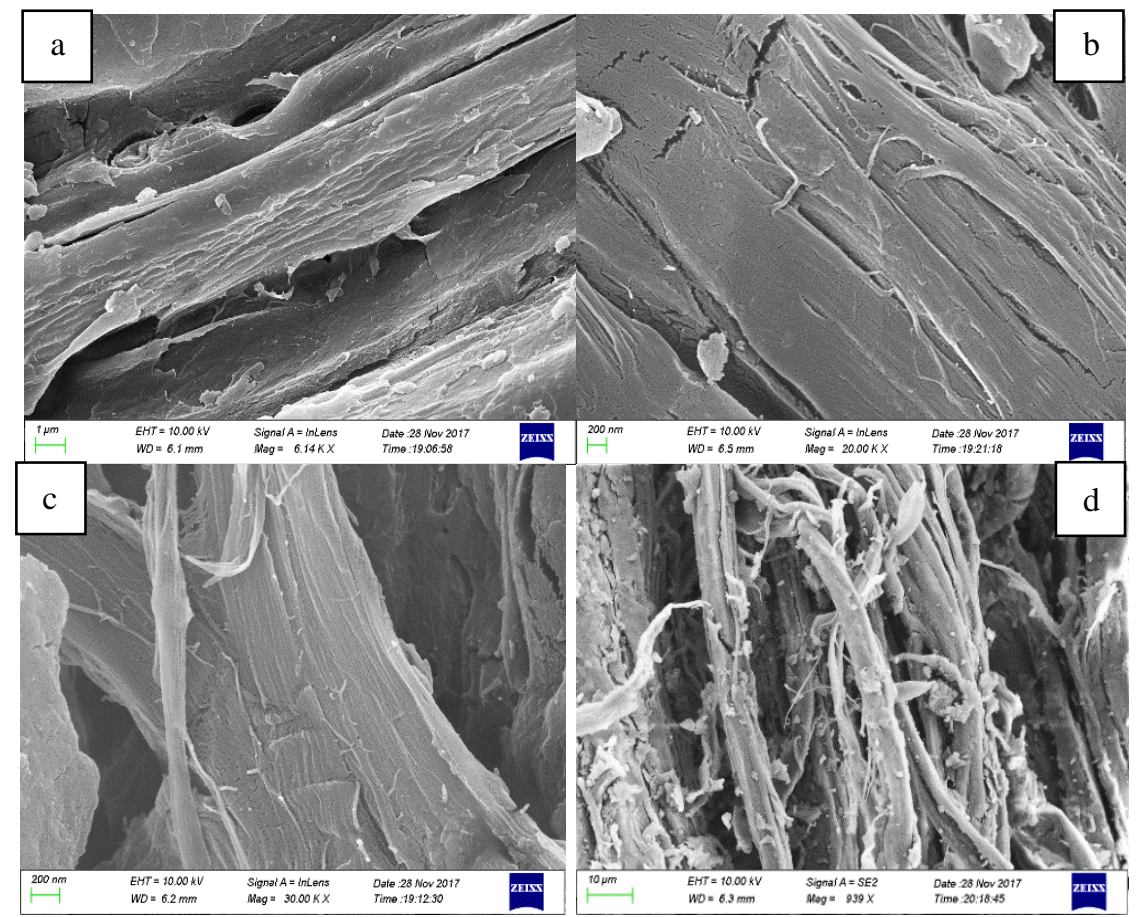

Figure 3. SEM micrographs of corn stalk before and after modification

Properties of briquette and formed coke

aExternal morphology and stove testing of briquette Figure 4 describes the external physical morphology of bio-briquette. The physical property of briquette as a cylindrical shape is diameter of $0.03 \mathrm{~m}$, height of $0.03 \mathrm{~m}$, mass $0.02 \mathrm{~kg}$, volume $0.000023 \mathrm{~m}^{3}$, density 910 $\mathrm{kg} / \mathrm{m}^{3}$, with dark black color and rough texture. The high density briquette is superior in terms of transportation, storage and handling. For equal volume, the high density of briquette fuel will generate higher heating value and longer period of burning [17]. The surface of briquette remains smooth flatten structures due to the high pressure. In addition, many fine cracks appear on the surface due to slight swelling of briquette removed from the mold attribute to elasticity of biomass fibers.

From Figure 5, it can be seen that raw coal has the highest burning time, while corn stalk has the lowest burning time. Result also reveals that addition of corn stalk reduces the burning time of the briquette. This proves that the biomasses have shorter burning time, and will ignite easily than raw coal.

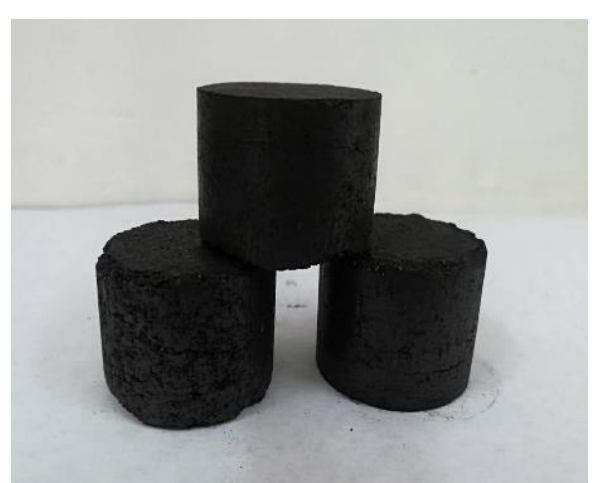

Figure 4. External morphology of bio-briquette
As the concentration of $\mathrm{NaOH}$ increases, the burning time eventually begins to decrease (ranging from $22 \sim 13 \mathrm{~min}$ ). It can be attributed to the higher concentration of $\mathrm{NaOH}$, the looser structure and higher porosity exhibited in binder. It leads to high porosity between coal particles and binders which enable easy percolation of oxygen and out flow of combustion briquettes. Compare with burning time, burning rate shows opposite trend as displayed in Figure 6. The corn stalk has highest burning rate due to biomass contains more volatile matter than coal and more porous allows for easy infiltration of oxygen. The observed values on burning rate reveals that to burn an equal mass of briquette is faster and easier with high $\mathrm{NaOH}$ concentration and short burning time. Beside, the time of boiling equal mass of water to $100^{\circ} \mathrm{C}$ of briquette decreases with the increases of $\mathrm{NaOH}$ concentration. The boiling time values of $1.5 \% \mathrm{NaOH}$ modified corn stalk preparation briquette, $2.0 \% \mathrm{NaOH}$ modified corn stalk preparation briquette, $2.5 \% \mathrm{NaOH}$ modified corn stalk preparation briquette is $15 \mathrm{~min}, 10 \mathrm{~min}$ and $7.5 \mathrm{~min}$, respectively. In general, the higher burning rate,

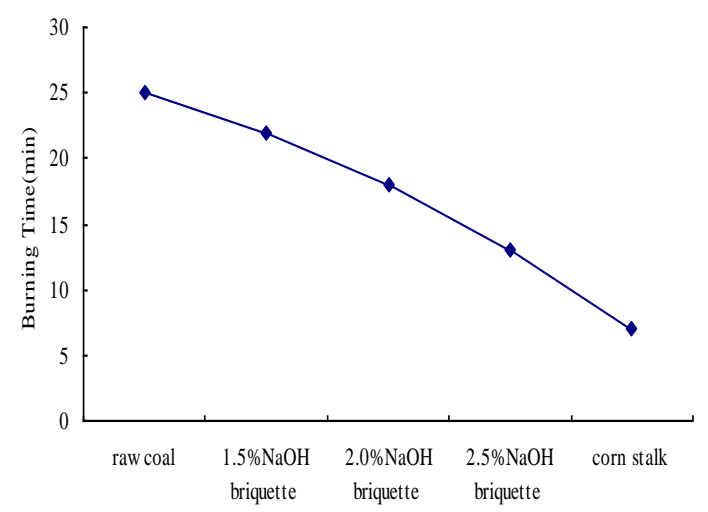

Figure 5. Burning time of bio-briquette 


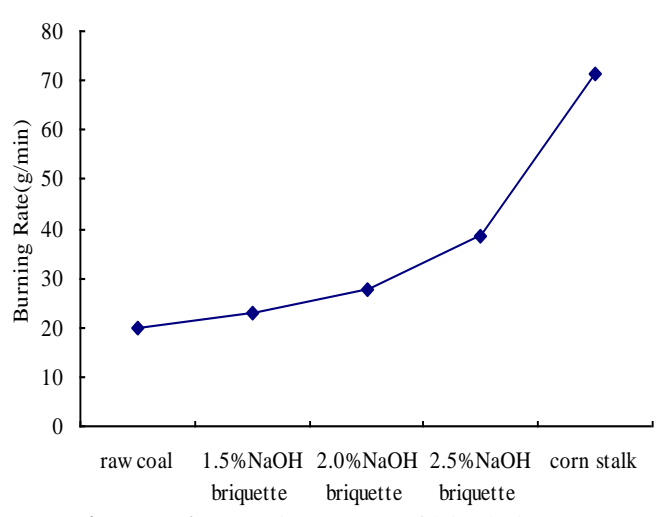

Figure 6. Burning rate of bio-briquette

the boiling time of water is shorter. Other characteristics of bio-briquette by eye observation are shown a good ignition with starter, ash in the form of dust and smoky, with strong flame. The corn stalk is showed the best ignition, ash and flame is the same as briquette fuel.

\section{FTIR analysis of briquette and formed coke}

Figure 7 describes FTIR spectrum of briquette and formed coke moulded by different Shenmu coal size of $3-1.5 \mathrm{~mm}$ and $<0.074 \mathrm{~mm}$, respectively. In general, the infrared spectrum of formed coke is simplier than briquette, and the absorption peak number is less and absorption strength is also weaker. This attribute to much more short branched chain and functional groups in briquette structure are pyrolyzed and released in the form of gaseous hydrocarbon during the early stage of pyrolysis. The formed coke structure is highly condensed and aromatized in final pyrolysis process resulting in the number of aromatic rings increased sharply and the ordering degree is further strengthened.
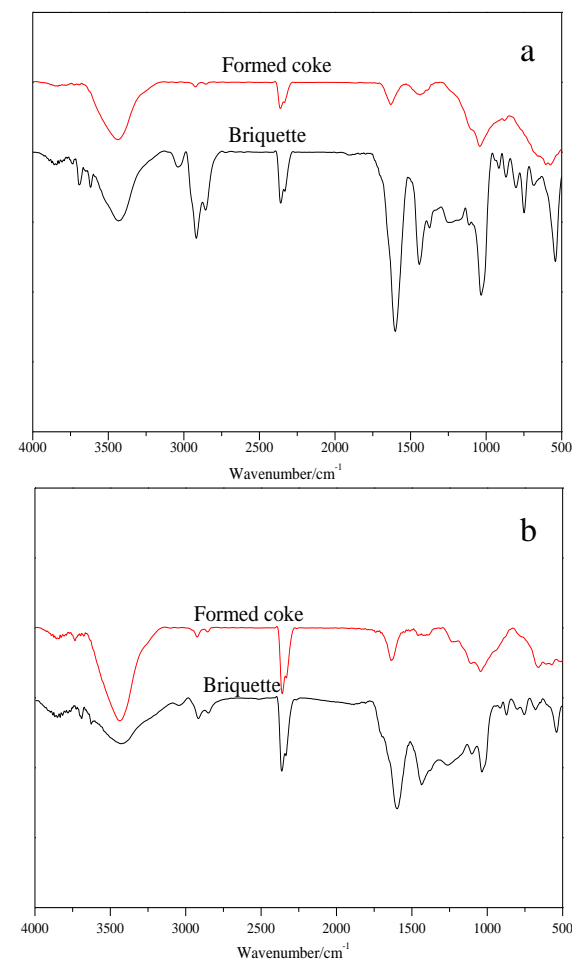

Figure 7. FTIR spectrum of briquette and formed coke
Due to the hydroxyl bond of phenol and alcohol are broke down and released in the form of gaseous small molecular during the briquette pyrolysis process, phenolic hydroxyl and alcoholic hydroxyl stretching vibration strength of briquette at $3400 \mathrm{~cm}^{-1}$ is higher than formed coke. In addition, the position of hydroxyl absorption peak shifts from $3200 \mathrm{~cm}^{-1}$ to $3400 \mathrm{~cm}^{-1}$ due to the hydroxyl exis ts in the form of as sociative structure of multimer that can form a large number of hydrogen bonds and similar supramolecular structure in briquette and formed coke [18]. To destory such structure requires more energy, which can not be ignored to stable formed coke network structure [19].

The aromatic C-H stretching vibration absorption strength at $3045 \mathrm{~cm}^{-1}$ is stronger in briquette, but dis appeared basically in formed coke. It illustrates that condensation degree of aromatic hydrocarbons is low in briquettes, which is only scattered low cyclic aromatic hydrocarbon. In the later stage of coking, due to polycondensation and aromatization are the main reaction, the number of aromatic ring increases dramatically, and short side chain and functional group release obviously. The absorption peak at $2858 \mathrm{~cm}^{-1} \sim$ $2951 \mathrm{~cm}^{-1}, 1450 \mathrm{~cm}^{-1}, 1375 \mathrm{~cm}^{-1}$ belongs to aliphatic $-\mathrm{CH}_{3}$ and $-\mathrm{CH}_{2}$ stretching vibration is stronger in briquette. It reveals that the briquette is mainly composed of aliphatic compounds, but formed coke is scarcely absorbed in this area due to aliphatic substances disappeargradually with volatile release during pyrolysis process [20]. Compare with formed coke, FTIR curve of briquette appears strong - $\mathrm{CN}$ absorption at $2381 \mathrm{~cm}^{-1}$, which disappear gradually during pyrolysis and mainly releases in the form of $\mathrm{NH}_{3}$ and $\mathrm{NO}$. Although formed coke is mainly made up of macromolecule fused ring aromatic hydrocarbon, framework vibration absorption of aromatic $\mathrm{C}=\mathrm{C}$ of briquette at $1510-1610 \mathrm{~cm}^{-1}$ is stronger due to the addition of corn stalk binder, which has a macromolecular space network structure, making a great contribution to absorption here. Ether bond stretching vibration strength at $1075 \sim 1128 \mathrm{~cm}^{-1}$ in briquette is also stronger than formed coke, indicating that pyrolysis simultaneously causes ether bond breakage .

The FTIR absorption strength of formed coke prepared by Shenmu coal with particle size $<0.074 \mathrm{~mm}$ at $3200-3600$ $\mathrm{cm}^{-1}, 2858 \mathrm{~cm}^{-1}-2951 \mathrm{~cm}^{-1}, 1450 \mathrm{~cm}^{-1}, 1375 \mathrm{~cm}^{-1}$ is stronger than that prepared by Shenmu coal with particle size 3-1.5 $\mathrm{mm}$. This attribute to even low porosity of fine-grained pulverized coal lead to small channel of volatile matter released. Thus, many small molecular hydrocarbon remain in formed coke that prepared by Shenmu coal with particle size $<0.074 \mathrm{~mm}$. The absorption strength of aromatic compounds at $1510 \sim 1610 \mathrm{~cm}^{-1}$ in formed coke from Figure $7 \mathrm{a}$ is quite similar to Figure $7 \mathrm{~b}$. It illustrates that there is no significant difference in size and structure of aromatic ring after condensation reaction. Observing absorption peak of characteristic functional groups of briquettes from Figures $7 \mathrm{a}$ and $7 \mathrm{~b}$, it is found that the smaller particle size of raw coal, the weaker absorption strength of functional groups. It also illustrates that over crushing raw coal has debilitation role on all components. briquette prepared by Shenmu coal with $3-1.5 \mathrm{~mm}$ and $<0.074 \mathrm{~mm}$ particle size and is magnified 1000 times, as 
shown in Figures $8 \mathrm{a}$ and $8 \mathrm{~b}$, respectively. The particle size of Shenmu coal is $3-1.5 \mathrm{~mm}$ and $<0.074 \mathrm{~mm}$, and the SEM micrograph of briquette From Figure 8 , it can be seen that the surface of briquette is rough and is made up of different size particles. The fiber structure of binder is mosaic or close adhesion with coal particles, and there are many voids or holes in briquette. In Figure 8a, the briquette is mainly composed of large particles and small particles are filled in the gap of large particles. The small particles mainly originate from two parts. One part is large particles in the mold are extruded and destroyed during the molding process. If molding pressure exceeds coal mechanical strength, some large particles are damaged to small particles. The other part of small particles is sugar, pectin and tannin that dissolved from corn stalk by $\mathrm{NaOH}$. In Figure 8 b, briquette is mainly made up of small coal particles which are closely bonded by binder, with high density and more is otropic structure.

Binder bonding mechanism can be thought that most lignin, a few hemicellulose and cellulose in corn stalk are dis solved by $\mathrm{NaOH}$ and liquid binder such as pectin and sugar is produced at the same time. The active groups from undecomposed cellulose and coal can form covalent bond or hydrogen bond, which increase briquette mechanical strength. Due to small coal particles can enter cellulose gully region or network structure, chemical bonds between them can form, and the intermolecular force is strengthened. However, binder and large coal particles that can not enter the cellulose network, can form mechanic meshing force which plays a bonding role.

SEM analysis of formed coke

SEM micrograph of formed coke prepared by Shenmu coal with $3-1.5 \mathrm{~mm}$ and $<0.074 \mathrm{~mm}$ particle size as shown in Figures 9a and 9b, respectively. In general, formed coke shows light gray metallic luster, light mass and small gap relatively among particles, and the epidermis is dense. This can be attributed to the colloid produced during the coking process which can flow enough, infiltrate and melt into coal particles to ensure the formed coke high mechanical strength. No biomass fiber is found in each photo, indicating that the binder participates in coke formation during carbonization process. That is to say the binder has a synergistic effect [21] with coal particles and forms carbon framework [22].

From Figure 9a, there are many obvious circular holes and small cracks inside the formed coke with large lump. From Figure 9b, there is no circular holes basically inside the coke with small lump. Due to the contact point of Shenmu coal with $3-1.5 \mathrm{~mm}$ particle size is less than Shenmu coal with $<0.074 \mathrm{~mm}$ particle size, the colloid produced by melting of fat coal and 4\# prime coking coal at high temperature can fully infiltrate and encapsulate Shenmu coal of $3-1.5 \mathrm{~mm}$. Besides, softening and melting binder is adsorbed onto the coal surface lead to the interspace between the particles is filled enough to form a dense and impermeable entity, which block the channels of organic group decomposition and escape during pyrolysis process [23, 24]. Thus, many holes of different sizes appear on the surface and inside [25]. Meanwhile, the large particle size of Shenmu coal $(3-1.5 \mathrm{~mm})$ can provide a free radical condensation place between binder and coal lead to molecules bonding fully and high strength briquette and formed coke obtained [26]. In addition, many tiny cracks appear on the surface of formed coke due to volume shrinkage behaviour take place seriously, the density of formed coke increases gradually at the same time. Besides, the volatile matter release promote the formation of cracks, and the minerals can cause cracks as well. More specifically,

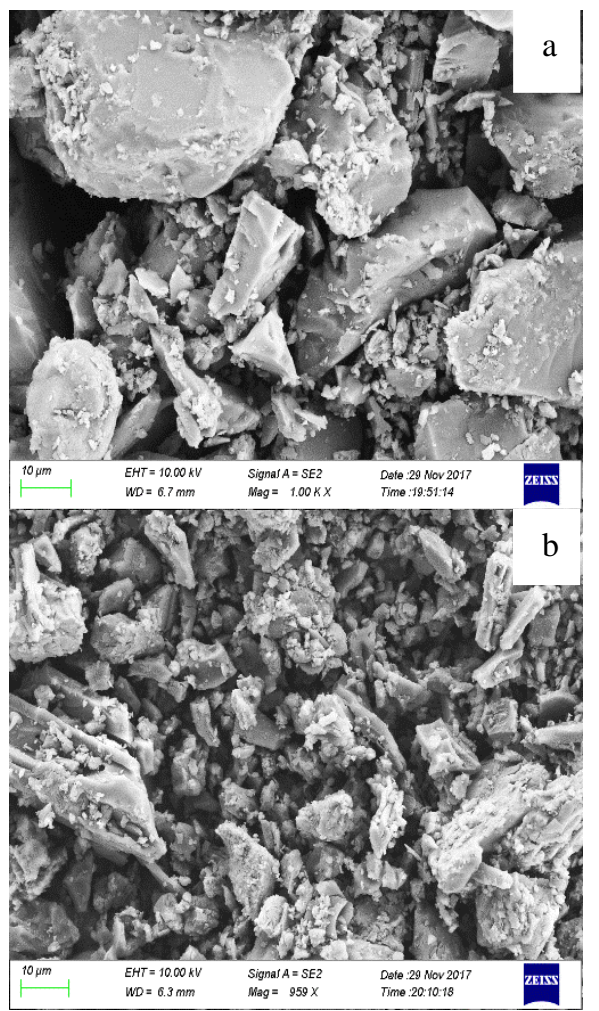

Figure 8. SEM micrographs of briquette

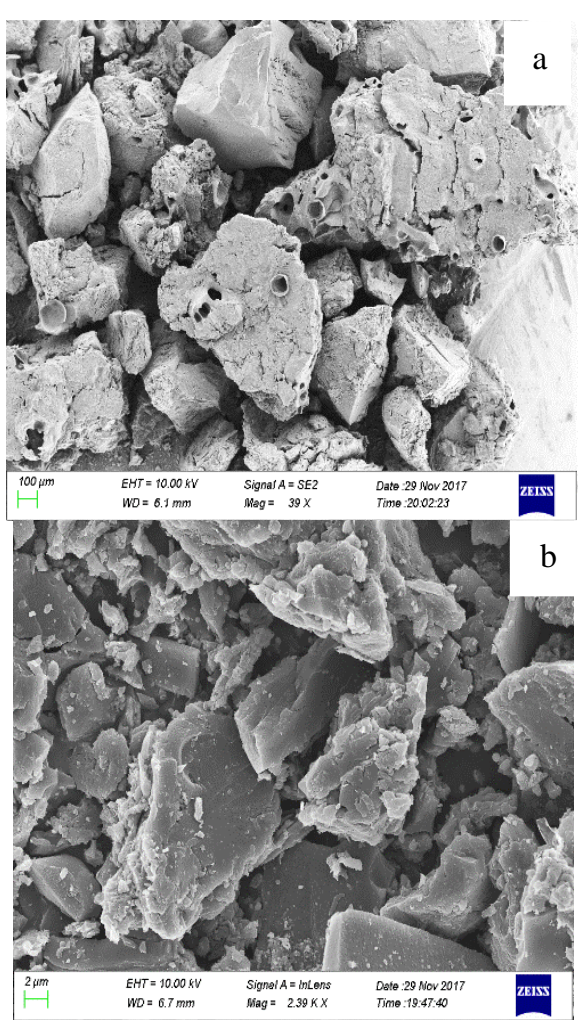

Figure 9. SEM micrographs of formed coke 
formed coke volume shrinkage is taking place, but the mineral belong to inorganic inert component with a certain mechanical strength in coal don't shrink. Thus, the mineral become crack center in the coke cake, causing the coke break easily [27]. Shenmu coal with particle size $<0.074 \mathrm{~mm}$ possesses much more inert contact points has not be softened and melted in coking process. Hence, little colloid can not fully infiltrate the surface and holes of coal particles, lead to formed coke strength is low. Furthermore, the channel of organic group release is not be blocked completely by colloid, so there is no hole in formed coke.

\section{CONCLUSION}

To produce lump coke from low-rank pulverized coal, the creation of high-quality briquettes are indispensable steps before coking and the creation of binder is an important step before moulding of coal. Micro-properties of modified corn stalk, briquette and formed coke were investigated in this study.

Compared with raw corn stalk, the moisture content and ash yield of modified corn stalk increases obviously and the volatile yield shows opposite trend. A $2.0 \% \mathrm{NaOH}$ modified corn stalk shows more voids or holes which can wrap a large number of coal particles. Besides, the strong interaction among fine fibers leads to the appearance of fibrils cross linking, which plays bonding and tension effect in briquetting process. Hence, the strong strength briquette obtains under high pressure.

The briquette combustion properties shows the addition of modified corn stalk reduces the burning time and increases burning rate with strong flame and short boiling time of water to $100^{\circ} \mathrm{C}$. From SEM micrograph, briquette has rough surface, and different sizes coal particles and fiber are bound together firmly. Formed coke shows light gray metallic luster, light mass, obvious circular holes and small gaps among particles. The melting colloid and binder can better infiltrate and encapsulate coal particles to form a dense and impermeable entity, which block the channels of organic group decomposition during pyrolysis process, thus forming many holes of different sizes on the surface and inside formed coke. The infrared spectrum of formed coke is simplier than briquette, and the absorption peak number is less and absorption strength is weaker also. This attribute to much more short branched chain and functional groups in briquette structure are pyrolyzed and released during the early stage of pyrolysis. The formed coke structure is highly condensed and aromatized in final pyrolysis process resulting in the number of aromatic rings increased sharply and the ordering degree is further strengthened.

\section{ACKNOWLEDGEMENTS}

This work was supported by the National Natural Science Foundation Project (21763030), Scientific Research Project of Key Laboratory of the Education Department of Shaanxi Province (17JS147) and Scientific Research Project of Key Laboratory of the Education Department of Shaanxi Province (18JS124).

\section{REFERENCE}

1. Minggao, Q.I.A.N., 2017. Efforts to be made to achieve the transition of Chinese coal industry from quantity to quality. China Coal, 43(7): 5-9.

2 Wu, W., Mo, R. and Wang, Z., 2002. Occurrence Features and Geological Work of Gemanium Resource in Yimin Coalfield, Inner Mongolia [J]. Geology of Inner Mangolia, 1: 618-628.

3 Baoqi, M., Xiongwei, L., 2014. The Developing Trend of China's semi-coke industry $[\mathrm{J}]$. Coal Processing and Comprehensive Utilization, 4: 22-26.

4 Zhang, Q., Yang, J., 2013. developing carbon industry in Yulin[J]. Industrial \& Science Tribune,8: 61-62.

5 Lela, B., Barišić, M. and Nižetić, S., 2016. Cardboard/sawdust briquettes as biomass fuel: Physicalmechanical and thermal characteristics. Waste Management, 47: 236-245.

6. Thabuot, M., Pagketanang, T., Panyacharoen, K., Mongkut, P. and Wongwicha, P., 2015. Effect of applied pressure and binder proportion on the fuel properties of holey bio-briquettes. Energy Procedia, 79: 890-895.

7. Gao, P., Zhou, Y., Meng, F., Zhang, Y., Liu, Z., Zhang, W. and Xue, G., 2016. Preparation and characterization of hydrochar from waste eucalyptus bark by hydrothermal carbonization. Energy, 97: 238-245.

8. Syafrudin, S., Zaman, B., Indriyani, I., Erga, A.S. and Natalia, H.B., 2015. The Utilization of Bottom Ash Coal for Briquette Products by Adding Teak Leaves Charcoal, Coconut Shell Charcoal, and Rice Husk Charcoal. Waste Technology, 3(1): 14-21.

9. Akuma, O. and Charles, M., 2017. Characteristic Analysis of Bio-coal Briquette (Coal and Groundnut Shell Admixtures). International Journal of Scientific Research in Science and Technology, 2(3): 30-38.

10. Jhadav, P.V., Dashore, S. and Chaudhary, K., 2016. Biomass Briquette System: Pollution Free Thermal Energy Resources. International Journal of Innovative Research in Science, Engineering and Technology, 5(1): 1165-1171.

11. Xinfu, H., Lei, Y., Hongju, W., Jianguo, W . and Anning, Z., 2016. Study on pyrolysis characteristics of biobriquette. Coal Science and Technology, 9: p.33-39.

12. Juan, C., Hao, L., Jian, L., Zhifang, Z. and Xiaohui, B., 2017. Research on corn stalk briquette binder of low metamorphic pulverized coals. China Coal, 4: 33-37.

13. Huang, G.X., Chen, L.J. and Cao, J., 2008. Briquetting mechanis $m$ and waterproof performance of bio-briquette. Journal of China Coal Society, 33(7): 812-815.

14. Chen, L.J., Chai, Y.Y. and Zhu, Z.H., 1997. Study of micro-structure of briquette. Journal of China Coal Society, 22(3): 304-307.

15. Lanying, P., 2009. An experimental study on using slime and crops' straw to produce bio-briquette. China Coal, 1: 61-63.

16. Zheng, L., Dang, Z., Yi, X. and Zhang, H., 2010. Equilibrium and kinetic studies of adsorption of Cd (II) 
from aqueous solution using modified corn stalk. Journal of hazardous materials, 176(1-3): 650-656.

17. Demirbaş, A., 1999. Properties of charcoal derived from hazelnut shell and the production of briquettes using pyrolytic oil. Energy, 24(2): 141-150.

18. Xiang, L.I., Qin, Z.H., Bu, L.H., Zhuang, Y.A.N.G. and Shen, C.Y., 2016. Structural analys is of functional group and mechanism investigation of caking property of coking coal. Journal of Fuel Chemistry and Technology, 44(4): 385-393.

19. Feng J., Li, W.Y., Xie, K.C., 2002. Research on coal structure using FT-IR. Journal of China University of Mining \& Technology, 31(5): 362-366.

20. Jones, J.M., Pourkashanian, M., Rena, C.D. and Williams, A., 1999. Modelling the relationship of coal structure to char porosity. Fuel, 78(14): 1737-1744.

21. Blesa, M.J., Miranda, J.L., Moliner, R., Izquierdo, M.T. and Palacios, J.M., 2003. Low-temperature co-pyrolysis of a low-rank coal and biomass to prepare smokeless fuel briquettes. Journal of Analytical and Applied Pyrolysis, 70(2): 665-677.
22. Zhijian, G., Xiao, M., and Ying, J., 2011. Optimization in selection of raw materials and binder for mould coke. Coal Processing \& Comprehensive Utilization, 6: 15-18.

23. Li, J., Yang, J. and Liu, Z., 2008. Hydro-treatment of a direct coal liquefaction residue and its components. Catalysis Today, 130(2-4): 389-394.

24. Soncini, R.M., Means, N.C. and Weiland, N.T., 2013. Co-pyrolysis of low rank coals and biomass: Product distributions. Fuel, 112: 74-82.

25. Li, J.G., Fang, Y.T., Zhang, Y.Q., Li, C.Y. and Wang, Y., 2008. Property of char from fast pyrolysis of direct coal liquefaction residue. Journal Fuel Chemistry Technology, 36(3): 273-278.

26. Wang, Y.F., Gao, J.S., Wu, C.L., Wu, D. and Xu, Y., 2000. Study on coking mechanism of anthracite formed coke. Journal of Fuel Chemistry and Technology, 28(3): 216-220.

27. Li, Y., Tang, X., 2001. Research factors affected to strength of coke. Coal Science and Ttechnology,4:23-26.

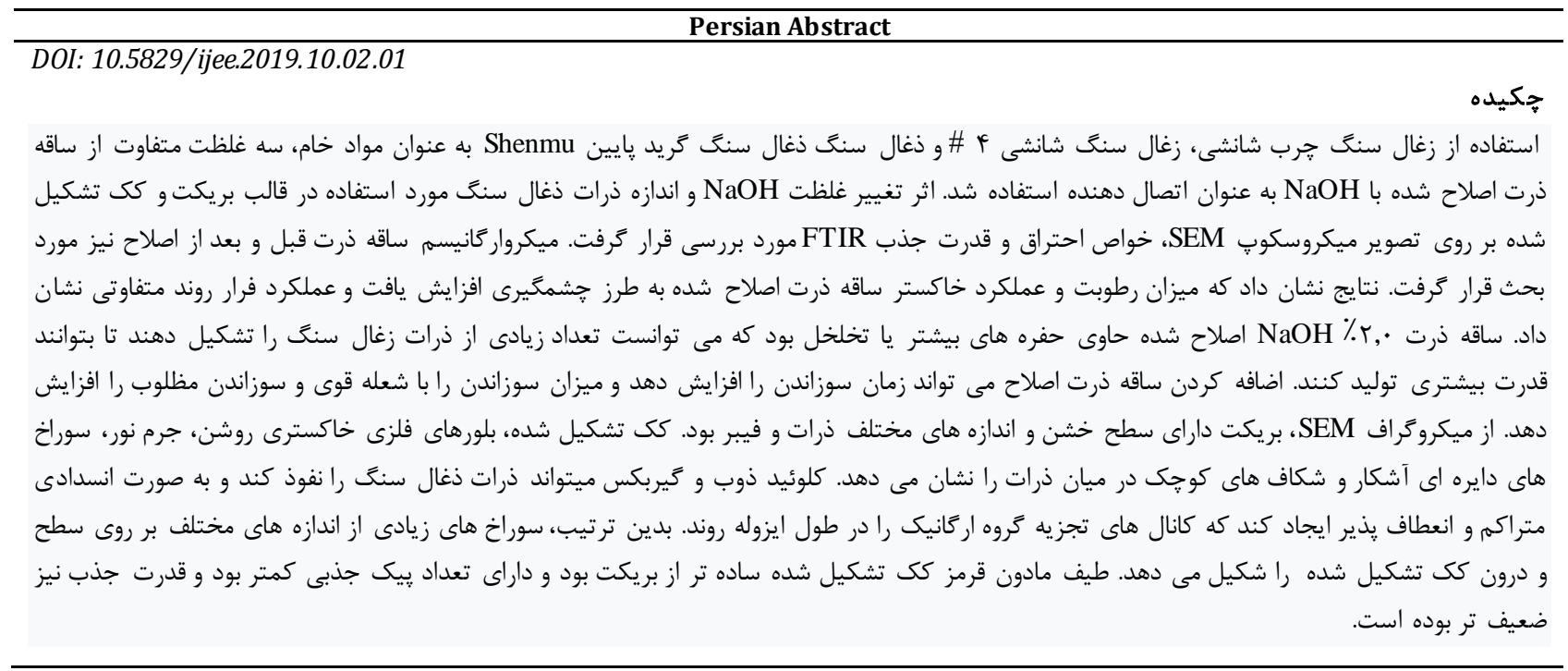

